\title{
Decorin suppresses lung metastases of murine osteosarcoma
}

\author{
KEN SHINTANI, AKIHIKO MATSUMINE, KATSUYUKI KUSUZAKI, JOJI MORIKAWA, \\ TAKAO MATSUBARA, TORU WAKABAYASHI, KENTARO ARAKI, HARUHIKO SATONAKA, \\ HIROKI WAKABAYASHI, TAKAHIRO IINO and ATSUMASA UCHIDA
}

Department of Orthopaedic Surgery, Mie University Faculty of Medicine, Tsu-City, Mie, Japan

Received November 27, 2007; Accepted January 24, 2008

\begin{abstract}
Lung metastasis is the most crucial event affecting the therapeutic outcome of osteosarcoma. The prevention of lung metastasis is therefore important in improving the prognosis of patients with osteosarcoma. Decorin is a major extracellular matrix protein which has become the focus of various cancer studies. The biological role of decorin in osteosarcoma has yet to be clarified. The aim of this study was to examine the potential of decorin as a novel biological target for the treatment of osteosarcoma. In this study, the LM8 murine osteosarcoma cell line (LM8) with high metastatic potential to the lung was used. The two cell lines established were LM8-DCN which stably expressed human decorin (hDCN) and LM8-mock, established as a control. The LM8-DCN cell line was subcutaneously injected into the backs of mice. Significantly fewer pulmonary metastases were observed in mice with LM8-DCN compared to mice inoculated with LM8 and LM8-mock $(\mathrm{P}<0.001)$. In addition, the mice in the LM8-DCN inoculated group survived significantly longer than those in the LM8 and LM8-mock inoculated group, based on the Kaplan-Meier survival analysis and log-rank tests $(\mathrm{P}<0.005)$. The effect of decorin on the growth rates, motility and invasion ability of LM8 was investigated in vitro. There was no difference in the morphology and growth rates, but the motility and invasion of LM8 were inhibited by decorin. These results suggest that decorin has the therapeutic potential to prevent lung metastasis in osteosarcoma.
\end{abstract}

\section{Introduction}

Osteosarcoma is a highly malignant bone tumor that most commonly affects adolescents and young adults. Although neoadjuvant and adjuvant chemotherapy and wide tumor excision have drastically improved the prognosis of patients

Correspondence to: Dr Akihiko Matsumine, Department of Orthopaedic Surgery, Mie University Faculty of Medicine, 2-174, Edobashi, Tsu-city, Mie, 514-8507, Japan

E-mail: matsumin@clin.medic.mie-u.ac.jp

Key words: decorin, metastasis, osteosarcoma with osteosarcoma, the prognosis for patients with lung metastasis remains poor, even if the patients were treated with aggressive protocols of chemotherapy (1-5). Therefore, the control of lung metastasis may have a major impact on improving the prognosis of patients with osteosarcoma.

The LM8 murine osteosarcoma cell line (LM8), established from the Dunn murine osteosarcoma cell line (Dunn), has a highly metastatic potential to the lung (6). In order to isolate the putative genes related to the lung metastases of osteosarcoma, genes that are differentially expressed between the Dunn and the LM8 were screened using a fluorescent differential display (FDD) technique. This showed that the expression of decorin mRNA in LM8 is down-regulated in comparison to that in Dunn.

Decorin is known to be able to influence the stromal structure through direct effects upon collagen fibril growth and assembly in vitro and in vivo (7). Decorin belongs to the small leucine-rich proteoglycan (SLRP) family, which is expressed in connective tissues, including the skin, cartilage and bone (8). Decorin is composed of a core protein and a single glycosaminoglycan (GAG) chain which is tissue-typespecific $(9,10)$. The core protein binds to various growth factors, including fibronectin (11), thrombospondin (12-14), transforming growth factor (TGF)- 3 (15), fibrinogen (16), pulmonary surfactant protein D (17), Wnt-1-induced secreted protein (WISP)-1 (18) and epidermal growth factor receptor (EGFR) $(12,19-24)$. In addition, the GAG chain binds to thrombospondin-1 $(13,14)$.

Decorin modulates growth factor activity and distribution via its TGF- $\beta$ binding properties $(15,19,25)$. Furthermore, decorin is believed to be a biological ligand for EGFR (1924,26). Decorin/EGFR interaction triggers a signal cascade leading to the activation of the mitogen-activated protein (MAP) kinase (21), mobilization of intracellular calcium (23), up-regulation of $\mathrm{p} 21^{\mathrm{WAF} 1 / \mathrm{CIP} 1}(\mathrm{p} 21)$, a potent inhibitor of cyclin-dependent kinases and ultimately growth suppression (19-22,26-28). While most cancer epithelial cells do not produce decorin (29-33), the ectopic expression of decorin has been shown to lead to the growth inhibition of the colon, glioma and ovarian cancer cells, presumably through a p21mediated mechanism $(21,23,28,34-37)$ or the down-regulation of the ErbB2 tyrosine kinase cascade $(26,28)$.

Clinical and pathological reports demonstrated that a reduced decorin expression facilitates tumorigenesis and growth in breast $(29,38-40)$, ovarian $(30)$, pancreatic $(31,32)$ and gastric cancer $(41)$, and squamous cell $(33,42)$ and 
hepatocellular carcinoma (43). Furthermore, in patients with breast cancer and soft tissue sarcoma, a reduced decorin expression is associated with a diminished prognosis $(38,44)$.

Although the relationship between decorin and tumorigenesis is being gradually elucidated, the biological role of decorin in lung metastasis which is the leading cause of death in patients with osteosarcoma has yet to be clarified. The present study was designed to investigate whether decorin inhibits migration and invasion in vitro and pulmonary metastasis in vivo using the LM8 cell line in order to verify the potential of decorin as a novel biological target for the treatment of pulmonary metastasis.

\section{Materials and methods}

Cells and animals. The Dunn (Dunn) and LM8 murine osteosarcoma cell lines (LM8) were used for the in vitro and in vivo experimental study. LM8, established from the Dunn cell line using Fidler's procedure (45), has a high metastatic potential to the lung (6). The two cell lines were maintained in Dulbecco's modified Eagle's medium (DMEM, Gibco) and supplemented with $10 \%$ fetal bovine serum (FBS, Gibco) in an incubator containing $5 \% \mathrm{CO}_{2}$ at $37^{\circ} \mathrm{C}$. Male inbred $\mathrm{C} 3 \mathrm{H}$ mice (Japan SLC, Shizuoka, Japan) aged 5 weeks were used for the in vivo study.

Reverse transcriptase polymerase chain reaction ( $R T-P C R)$ analysis. Total RNA was isolated from the Dunn and LM8 cell lines by a modified, single-step acid guanidine thiocyanatephenol-chloroform method using an Isogen reagent (Nippon Gene, Japan) according to the manufacturer's protocol. The RNA was reverse transcribed using an Oligo(dT) primer, according to the manufacturer's protocol (SuperScript firststrand synthesis system for RT-PCR, Invitrogen). The PCR of decorin was carried out on a DNA thermal cycler (Takara PCR thermal cycler MP). The amplification profile consisted of 25 cycles at $93^{\circ} \mathrm{C}$ for $30 \mathrm{sec}, 50^{\circ} \mathrm{C}$ for $10 \mathrm{sec}$ and $72^{\circ} \mathrm{C}$ for 1 min. Primers 5'-CAC CAC CCC CTC CTC CTT CT-3' and 5'-CGC CCA GTT CTA TGA CAA GCA-3' were designed to amplify the decorin. The expression levels of the housekeeping gene, $B$-actin, were quantitated in the same reaction wells.

Construction of the decorin expression vector and generation of stable clones. The two cell lines established were LM8-DCN which stably expressed human decorin (hDCN) and LM8mock established as a control. The hDCN gene was amplified by PCR using a pair of oligonucleotide primers containing BamHI and EcoRI restriction sites, using pORF-hDCN (Invitrogen, San Diego, USA) as a template. After digestion with BamHI and EcoRI, the hDCN gene was inserted into the multiple cloning sites of the p3XFLAG-CMV-14 expression vector (Sigma, USA). The p3XFLAG-CMV-9 expression vector (Sigma) was used as a control vector.

Gene transfection was performed using Lipofectamine 2000 according to the manufacturer's instructions (Invitrogen). After transfection the cells were incubated with a non-selective medium for $48 \mathrm{~h}$ and the culture medium was changed to a selective medium containing G418 $(800 \mu \mathrm{g} / \mathrm{ml})$. After colony formation, independent colonies were isolated using cloning cylinders, treated with $0.25 \%$ trypsin and transferred to microtiter wells. The isolated clones were maintained routinely with G418 (300 $\mu \mathrm{g} / \mathrm{ml})$.

Western blotting. The expression of decorin protein was determined using Western blotting. Cells $\left(1 \times 10^{6}\right)$ suspended in $10 \mathrm{ml}$ DMEM supplemented with $10 \%$ FBS were seeded on 100 -mm plastic dishes. The following day, the culture medium was changed to $7 \mathrm{ml}$ of serum-free medium. After incubation at $37^{\circ} \mathrm{C}$ for $24 \mathrm{~h}$, the conditioned medium was collected. Recombinant human decorin protein (R\&D systems, AF143-DE) was used as a positive control. After digestion of the collected medium with $0.1 \mathrm{U} / \mathrm{ml}$ chondroitinase $\mathrm{ABC}$ (Seikagaku, Japan) for $60 \mathrm{~min}$ at $37^{\circ} \mathrm{C}$ to remove chondroitinand dermatan-sulfate chains, it was mixed with an SDS sample buffer (0.5 M Tris-HCl, pH 6.8, 10\% SDS, 30\% glycerol, $9.3 \%$ dithiothreitol and $0.00012 \%$ bromophenol blue) at the ratio of 1:5 and boiled for $5 \mathrm{~min}$. The samples were separated in $10 \%$ sodium dodecyl sulfate polyacrylamide gel electrophoresis (SDS-PAGE) and transferred onto polyvinilidene difluoride (PVDF) membranes (Millipore Corporation, Bedford, MA). After blocking the membrane with TBS-T (20 mM Tris-HCl, pH 7.6 and 1\% Tween-20) containing 5\% non-fat dried milk for $1 \mathrm{~h}$ at room temperature on an orbital shaker, the membrane was rinsed three times with TBS-T at room temperature for $5 \mathrm{~min}$. Immunodetection was performed using anti-mouse decorin antibody (AF1060, R\&D Systems Inc, USA), anti-human decorin antibody (AF143 and R\&D Systems Inc) and anti-FLAG M2 monoclonal antibody (Sigma). The membrane was immersed in the first antibody solution overnight at $4{ }^{\circ} \mathrm{C}$. After washing with TBS-T, the membranes immunoblotted by goat antibody (AF1060 and AF143) were incubated with 1:2500 horseradish peroxidase (HRP) conjugated rabbit anti-goat antibody (Dako Cytomation) for $1 \mathrm{~h}$ at room temperature. The membrane immunoblotted by the mouse antibody (anti-FLAG M2 monoclonal antibody) was incubated with 1:2500 HRP conjugated sheep antimouse antibody (Amersham Biosciences). The bands were visualized using ECL plus a Western blotting detection system (Amersham Biosciences) and detected by LAS-1000 plus (Fujifilm, Tokyo, Japan).

Pulmonary metastasic assay in vivo. LM8 cells, LM8-mock and LM8-DCN were injected subcutaneously ( $1 \times 10^{7}$ cells per mouse) into the back space of ten male $\mathrm{C} 3 \mathrm{H}$ mice at 5 weeks of age, respectively. The tumor size was measured every week. The tumor volume was calculated with the following formula: tumor volume $\left(\mathrm{mm}^{3}\right)=0.5 \mathrm{xaxb}^{2}$ ( $\mathrm{a}$ and $\mathrm{b}$ being the longest and shortest diameters of the tumor, respectively). After the subcutaneous tumors and the lungs were removed 4 weeks later, they were fixed in $10 \%$ formalin and embedded in paraffin. The paraffin-embedded lung tissues were cut at their maximum dimensions. The specimens were stained with hematoxylin and eosin and the number of lung metastatic nodules was counted microscopically.

Survival assay in vivo. Each of the three tumor cell lines $\left(1 \times 10^{7}\right.$ cells per mouse) was inoculated subcutaneously into the back space of ten male $\mathrm{C} 3 \mathrm{H}$ mice. The overall survival (OS) was defined as the time from the tumor cell inoculation to the date of death attributed to the tumors. For a prognostic 
analysis, the Kaplan-Meier survival analysis and log-rank tests were performed.

Cell growth curve analysis. Each of the cell lines were seeded on a $35-\mathrm{mm}$ dish at a density of $1 \times 10^{4} /$ dish in DMEM supplemented with $10 \%$ FBS. The medium was changed every two or three days. On days 3, 5, 7, 9 and 11, the cells were harvested and counted with a hemocytometer (Nitirin, Tokyo) using a phase-contrast light scope. Three dishes for each of the cell lines were simultaneously counted. The average numbers were plotted and the results were statically analyzed.

Cell motility and invasion assay in vitro. The cell motility and invasion assays were performed using Biocoat migration chambers with multiple pores of $8-\mu \mathrm{m}$ diameter in the membranous bottom surface of the cell culture inserts.

To investigate the cell motility, each of the cell lines was re-suspended in DMEM with $0.1 \%$ bovine serum albumin (BSA) in the upper chambers. The lower chambers were filled with DMEM containing fibronectin $(20 \mu \mathrm{g} / \mathrm{ml})$ and incubated at $37^{\circ} \mathrm{C}$ in a $5 \% \mathrm{CO}_{2}$ incubator. After $12 \mathrm{~h}$ (for the motility assay) or $24 \mathrm{~h}$ (for the invasion assay), the migrant cells on the undersurface of the membrane were fixed with $10 \%$ neutral-buffered formalin-fixative and stained with diffQuick stain (Baxter). The membranes were mounted on the glass slides and the glued cells on the membranes were counted in 10 random microscopic fields (magnification, $\mathrm{x} 100$ ) for the motility assay and from 5 random microscopic fields for the invasion assay.

Prior to the invasion assay, the upper membranous surface of the cell culture inserts were coated with matrigel matrix, BD BioCoat ${ }^{\mathrm{TM}}$ Matrigel $^{\mathrm{TM}}$ invasion chambers (BD Biosciences Discovery Labware, Bedford, MA). After the suspension of each cell line followed by a $24 \mathrm{~h}$ incubation at $37^{\circ} \mathrm{C}$ in a $5 \% \mathrm{CO}_{2}$, the migrant cells on the undersurface were fixed and stained with diff-Quick stain (Baxter). The adherent cells on the membranes were counted from five random microscopic fields (magnification, x100).

Statistical analysis. Any association between the variables was determined by a Mann-Whitney test. For a prognostic analysis, the Kaplan-Meier survival analysis and log-rank tests were performed. The analysis was performed using StatView statistical software (version 5.0, SAS Institute Inc., Cary, NC). Differences were considered significant for $\mathrm{P}<0.05$.

\section{Results}

Expression of decorin in the Dunn and LM8 murine osteosarcoma cell lines. Since the expression of decorin mRNA in LM8 cells is down-regulated in comparison to that of the Dunn cells (unpublished data), the decreased expression level of decorin mRNA in LM8 cells was confirmed using RT-PCR (Fig. 1A). In addition, the reduction of the decorin protein expression in LM8 cells was confirmed using Western blot analysis (Fig. 1B).

Isolation of decorin expressing LM8 cell lines. To examine the biological effect of decorin on osteosarcoma cells, the subclones of LM8-DCN cell lines which stably express the
(A)

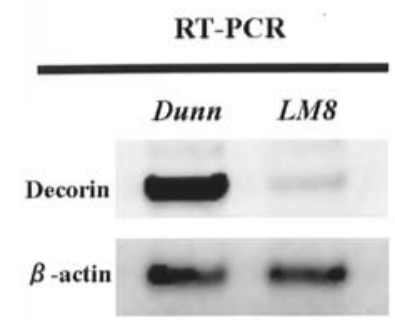

(B)
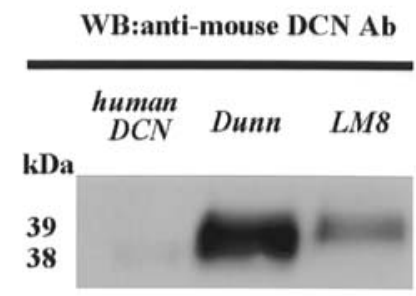

Figure 1. The expression of decorin in Dunn and LM8 murine osteosarcoma cell lines. (A) The decorin gene expression detected by RT-PCR. (B) Decorin protein expression detected by Western blot analysis. These data confirmed that the expression level of decorin in the the LM8 cells was lower than that of the Dunn cells.
(A)

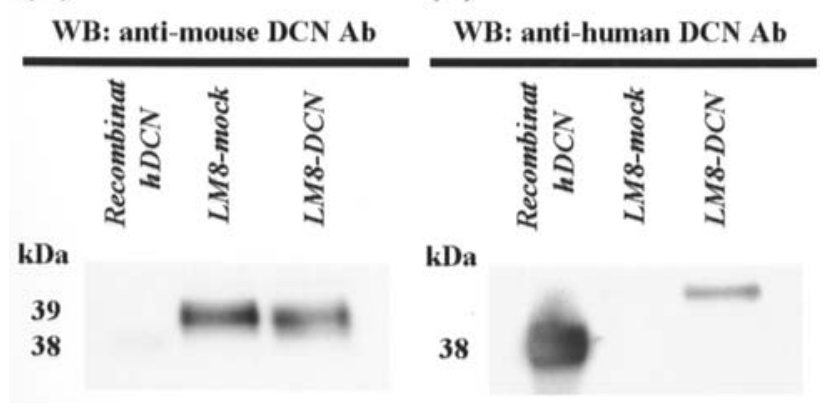

Figure 2. The isolation of decorin expressing LM8 cell lines. After isolation of the 2 types of subclones of LM8, LM8-DCN, which stably expresses the decorin protein and LM8-mock, the decorin-protein expression, was examined using Western blot analysis. There was no difference in the expression of the mouse decorin observed between LM8-mock and LM8-DCN (A). However, the human decorin expression was found only in LM8-DCN (B).

decorin protein were isolated. Among the six isolated subclones, the three clones that produced a sufficient amount of decorin protein were used for the following experiment (data not shown). Western blotting showed that there were no differences in the level of expression of mouse decorin protein between LM8-mock and LM8-DCN (Fig. 2A). However, the human decorin expression was found only in the LM8-DCN cells (Fig. 2B).

The morphological differences between each cell line were examined. No morphological differences were noted between LM8, LM8-mock and LM8-DCN cells when they were cultured on plastic dishes (Fig. 3).

Inhibitory effect of decorin on pulmonary metastasis in vivo. Since decorin expression is lower in LM8 than in Dunn, it is possible that decorin protein has anti-metastatic properties in the lung. Therefore, to investigate whether decorin protein inhibits the lung metastases of LM8 in vivo, a pulmonary metastasic assay was performed. Although multiple pulmonary metastases were formed on all the cell lines 4 weeks after inoculation, significantly fewer pulmonary metastases were observed in mice inoculated with LM8-DCN cells than those inoculated with the LM8 and LM8-mock cell lines $(\mathrm{P}<0.001)$. The mean number of nodules on the lungs at their maximum 


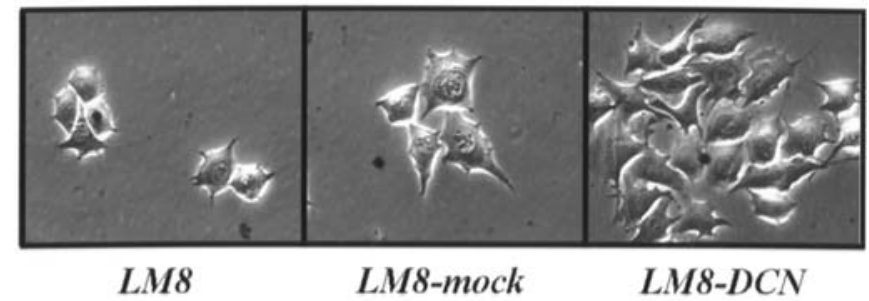

Figure 3. No morphological differences were noted between LM8, LM8mock and LM8-DCN when cultured on plastic dishes.

A

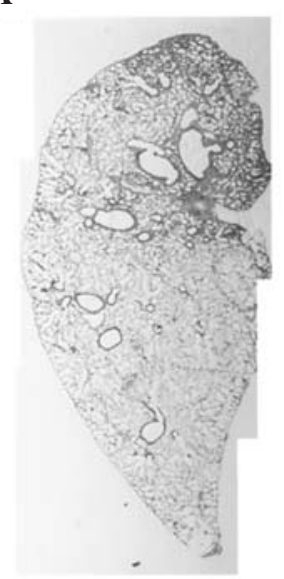

LM8-DCN

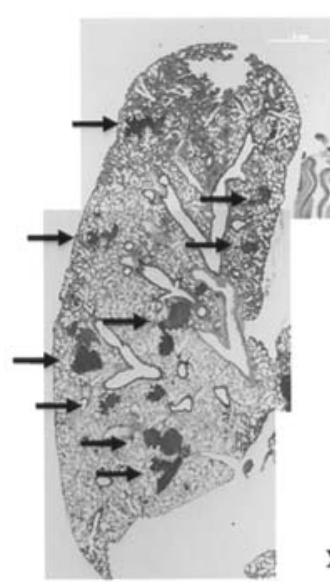

LM8-mock $\mathbf{x} 20$

B

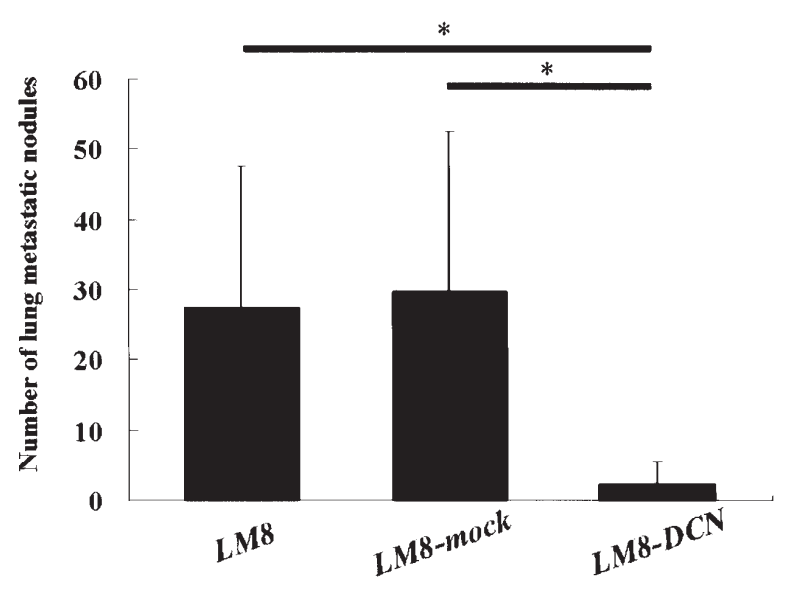

Figure 4. In vivo effect of decorin on the pulmonary metastasis of murine osteosarcoma. (A) A microphotograph of pulmonary metastases in mice with LM8-DCN and LM8-mock. (B) The inhibitory effect of decorin on lung metastasis in murine osteosarcoma. The mean number of lung metastatic nodules 4 weeks after tumor cell inoculation was significantly reduced in mice inoculated with LM8-DCN cells compared to those inoculated with LM8 or LM8-mock cells. The mean number of nodules on the lung at their maximum dimensions was $27.4 \pm 20.8$ with LM8, 29.8 \pm 22.7 with LM8-mock and 2.4 \pm 3.03 with LM8-DCN. ${ }^{*} \mathrm{P}<0.001$ as compared to the LM8 and LM8mock.

dimensions was $27.4 \pm 20.8$ in mice inoculated with the LM8

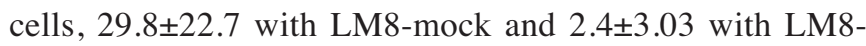
DCN (Fig. 4A and B).

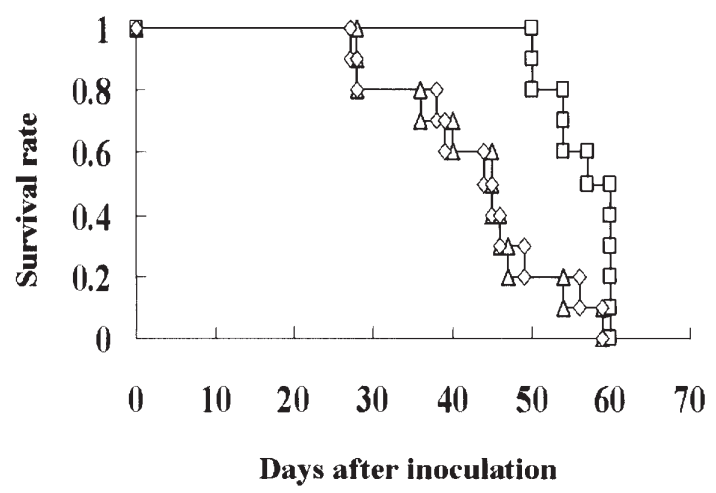

Figure 5. The survival curves for LM8, LM8-mock and LM8-DCN. The survival curves for mice inoculated with LM8 $(\diamond)$, LM8-mock $(\square)$ and LM8-DCN $(\triangle)$ were calculated by the Kaplan-Meier test. The mice with LM8-DCN survived significantly longer than mice with LM8 and LM8mock, ${ }^{*} \mathrm{P}<0.005$ (log-rank test).

No histological differences of the primary and lung metastatic lesions were observed among the cell lines.

Survival of LM8, LM8-mock and LM8-DCN cell-bearing mice. The survival of LM8, LM8-mock and LM8-DCN cellbearing mice was examined. The mean survival time was $43.1 \pm 10.5$ days in mice inoculated with LM8 cells, $42.8 \pm 10.1$ with LM8-mock and $56.5 \pm 4.2$ with LM8-DCN after tumor cell inoculation. The mice in the LM8-DCN inoculated group survived significantly $(\mathrm{P}<0.005)$ longer than those in the LM8 or LM8-mock inoculated group, based on the KaplanMeier survival analysis and log-rank tests (Fig. 5). These data suggest that decorin significantly improved the survival time of mice by reducing lung metastases.

Cell growth curve analysis in vitro and in vivo. To clarify the reason for pulmonary metastases being significantly suppressed in mice inoculated with LM8-DCN in comparison to mice inoculated with LM8 and LM8-mock, the cell growth rate of the three cell lines was compared in vitro and in vivo. Cell growth rates in vitro were not statistically different among the three cell lines (Fig. 6A). In addition, the subcutaneously inoculated tumor volume showed no significant differences among the cell lines (Fig. 6B).

Inhibitory effect of decorin on cell motility and invasion in vitro. To clarify the reason for the differences of the lung metastatic potential among the three cell lines, the motility and invasion capacity of the each cell line was determined by examining migration through an $8-\mu \mathrm{m}$ diameter pore-size membrane coated with matrigel. Decorin inhibited the LM8 cell motility and invasion ability promoted by $\mathrm{FN}(\mathrm{P}<0.05)$ (Fig. 7A and B). These results suggest that decorin suppressed lung metastases by reducing cell migration and invasion through an interaction with FN.

\section{Discussion}

The prognosis of patients with osteosarcoma has improved with the advancement of diagnostic techniques, aggressive chemotherapy and the wide excision of tumors. Nevertheless, 
A

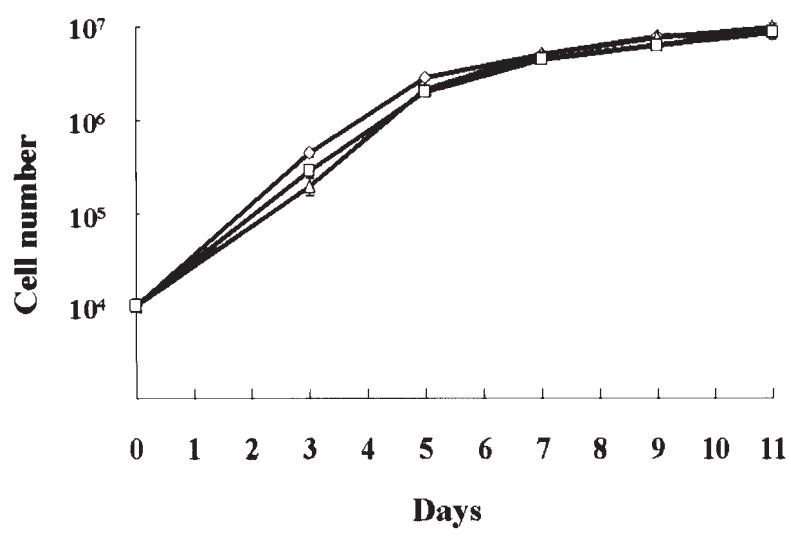

B

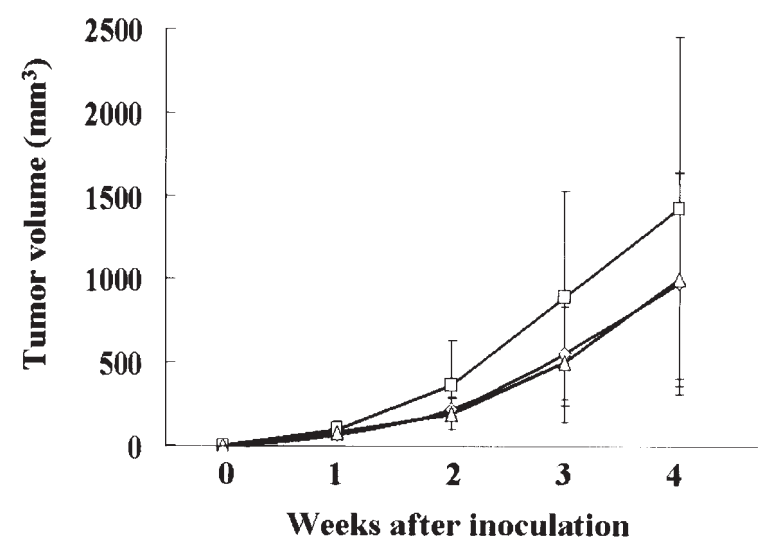

Figure 6. Cell growth analysis in vitro and in vivo. (A) The cell growth curve of the LM8 $(\diamond)$, LM8-mock $(\square)$ and LM8-DCN $(\triangle)$ cells in vitro. Three dishes for each cell line were simultaneously counted every other day. The mean values \pm SD were plotted. No significant difference was observed among the cell lines. (B) The growth of the subcutaneous tumors following inoculation with the LM8 $(\diamond)$, LM8-mock $(\square)$ and LM8-DCN $(\triangle)$ cells. Tumor volumes were calculated as: tumor volume $\left(\mathrm{mm}^{3}\right)=0.5 \mathrm{xaxb}^{2}(\mathrm{a}$ and $\mathrm{b}$ being the longest and shortest diameters of the tumor, respectively). During this experiment, there were no significant differences in the subcutaneous tumor volume among the cell lines.

the prognosis for patients with metastatic lesions treated with conventional chemotherapy and surgery remains poor (46). Lung metastasis is the most crucial factor affecting the survival of patients with osteosarcoma. To improve the prognosis of patients with osteosarcoma, the establishment of a new therapeutic strategy for the prevention of lung metastasis is essential. Therefore, the genes that are differentially expressed between the Dunn cell line and LM8 which has a highly metastatic potential were screened using a FDD technique. This showed a reduced expression of decorin in LM8. Decorin is a major extracellular matrix protein and plays an important role in maintaining a normal collagen structure $(11,12,25,47,48)$. Recently, the anti-tumor effect of decorin was seen in diverse malignant tumors. Consequently, there is great interest in decorin as a natural anti-tumor product with low toxicity that can be used in combination with current chemotherapy.
A

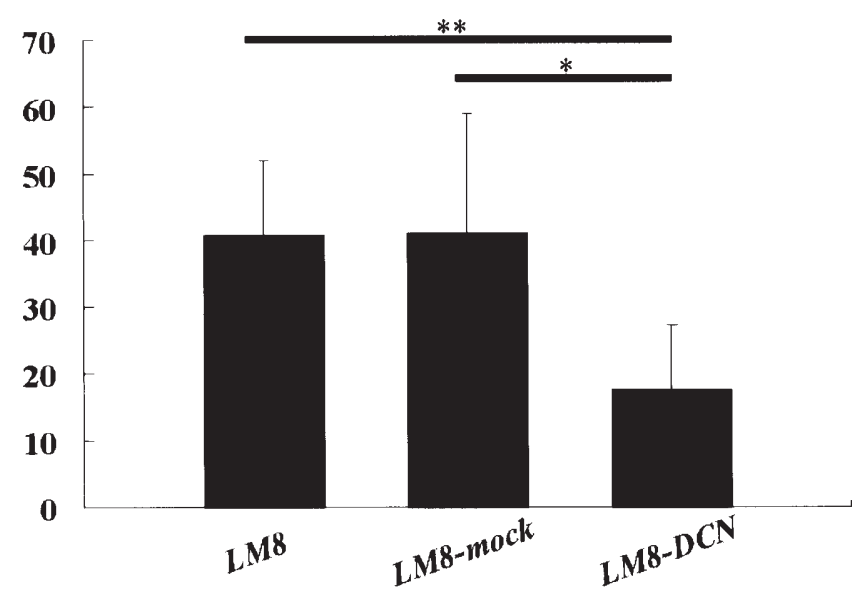

B

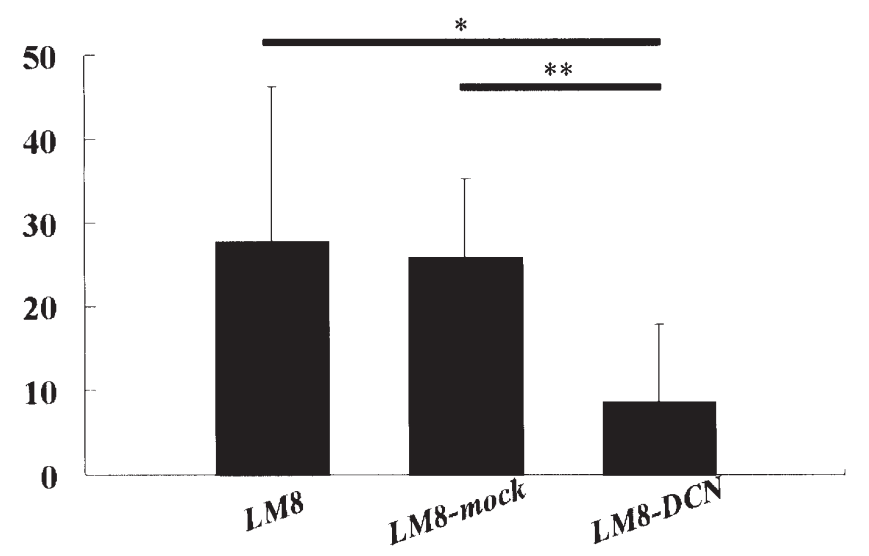

Figure 7. The inhibitory effect of decorin on cell motility and invasion in vitro. (A) The inhibitory effect of decorin on cell motility. After the suspension of each cell line followed by a $12 \mathrm{~h}$ incubation at $37^{\circ} \mathrm{C}$ in $5 \% \mathrm{CO}_{2}$, the migrant cells on the undersurface were fixed and stained with diff-Quick stain (Baxter). The attached cells on the undersurface of the membranes were counted from 10 random microscopic fields (magnification, x100). (B) The inhibitory effect of decorin on cell invasion. After the suspension of each cell line followed by a $24 \mathrm{~h}$ incubation at $37^{\circ} \mathrm{C}$ in $5 \% \mathrm{CO}_{2}$, the migrant cells on the undersurface were fixed and stained with diff-Quick stain. The adherent cells on the membranes were counted from five random microscopic fields (magnification, x100). Decorin inhibits the LM8 cell motility and invasion ability ( ${ }^{*} \mathrm{P}<0.05$ using the Mann-Whitney test).

The LM8-mock and LM8-DCN cell lines were initially cloned to investigate whether decorin suppressed tumor growth or lung metastases. The results showed that decorin significantly prevented lung metastases when it was inoculated into the subcutaneous space on the backs of $\mathrm{C} 3 \mathrm{H}$ mice. Furthermore, the survival time of the LM8-DCN-bearing mice was significantly improved.

This potent inhibitory effect of decorin on lung metastasis suggested that this effect may be due to retarded tumor growth in vitro and in vivo, because many authors have reported that decorin effectively inhibits the in vitro growth of cancer cell lines, including squamous carcinoma cells $(20,21)$, ovarian cancer $(49)$, colon carcinoma cells $(22,34)$, breast $(28,39)$ and pancreatic cancer (31) and the in vivo growth of colon $(26,34)$, squamous cell carcinoma $(20,26)$, lung, liver (50) and breast 
cancer $(28,39)$ fibrosarcoma (37) and uterine cervical cancer (37). However, surprisingly there were no statistical differences in the cell growth rates either in vitro or in vivo observed among the LM8, LM8-mock and LM8-DCN cell lines. Osteosarcoma cell lines usually produce more decorin protein than epithelial cancer cell lines, because decorin is one of the crucial extracellular matrix proteins required to produce woven bone (51). Therefore, osteosarcoma cells may respond differently to the ectopic expression of decorin with regards to cell growth, as compared to the epithelial cancer cell lines. Further investigations are therefore required.

Angiogenesis and microvessel density are correlated with cancer metastases in breast and lung carcinoma $(52,53)$. VEGF and microvessel density are correlated with pulmonary metastasis in human osteosarcoma (54) and the expression levels of VEGF mRNA were higher in the LM8 cells than in the maternal Dunn cells (6). In contrast, decorin influences different signaling pathways, leading to the survival and differentiation of vascular endothelial cells $(35,37)$. Decorin suppresses VEGF production and neovascularization in vitro and in vivo (37). Further studies examined the neovascularization of the inoculated tumor, by immunohistochemically staining the endothelial cells with anti-factor VIII antibody to determine whether the anti-metastatic effect of decorin is associated with the down-regulation of neovascularization. It was not possible to statistically define the differences of vascular endothelial cell migration of the inoculated tumors between the LM8 and LM8-DCN cells (data not shown). It is possible that the inhibitory effect on the induction of the vascular endothelial cells by decorin may depend on the posttranslational modification of decorin (18).

To clarify the differences in the lung metastatic potential among the three cell lines, the motility and invasion capacity of each cell line was examined. This demonstrated that decorin inhibited the LM8 cell motility and invasion ability promoted by FN. These results suggest that decorin suppressed lung metastases by reducing cell migration and invasion by interacting with FN. Cell migration is controlled by growth factors and cell adhesive interactions, which are mediated by cell surface receptors, such as integrins and syndecan-4 (55). Kinsella et al reported that the migration of endothelial cells that express decorin is significantly inhibited in the monolayer outgrowth and microchemotaxis chamber assays (55). Endothelial cells that express decorin assemble an extensive fibrillar fibronectin matrix more rapidly than the control cells. Another study reported that decorin has an inhibitory effect on the cell migration of the MG-63 osteosarcoma cell line and the decorin-bearing dermatan-sulfate chains are $\sim 20$-fold more effective in inhibiting cell migration than decorin-bearing chondroitin-sulfate chains (56). Additionally, the migration of cancer cells has been demonstrated to be regulated through EGF/FGFR, wnt/ $ß$-catenin, integrin, TGF- $\beta$ signaling and their cross talk (57). Further investigations are required to determine whether the effects of decorin observed in the present study involve interactions with these pathways.

Decorin and its derivatives have several advantages as a new therapeutic anti-tumor molecular target. First, decorin has minimum toxicity. In the present study, LM8-DCN-inoculated mice showed no loss of body weight nor was any toxicity detected in blood examinations (data not shown). It is possible that this may be because decorin is a naturally ubiquitous proteoglycan. Second, decorin was shown to synergize with carboplatin to inhibit the growth of ovarian tumor cells (49). If decorin is to be used for the treatment of osteosarcoma patients, one option would be to use decorin as a supplemental drug with other chemotherapeutic agents. Decorin may enhance the anti-tumor effect of carboplatin which is one of the standard chemotherapeutic agents utilized for osteosarcoma. Further investigations are necessary to determine the optimum therapeutic benefits of decorin.

In conclusion, this study demonstrated the inhibitory effect of the decorin protein on lung metastasis in the osteosarcoma cell lines. The mechanism of inhibition was due to a reduced cell motility and invasion by decorin. Decorin is a natural product and has no immunogenicity. Therefore, these results suggest that decorin represents a new therapeutic modality to prevent pulmonary metastasis in osteosarcoma. Additional studies are needed to clarify the mechanism of the inhibitory effect of decorin on the lung metastasis of osteosarcoma.

\section{Acknowledgements}

We thank the secretarial staff of the Department of Orthopaedic Surgery, Mie University Faculty of Medicine, for their generous cooperation.

\section{References}

1. Rosen G, Huvos AG, Mosende C, et al: Chemotherapy and thoracotomy for metastatic osteogenic sarcoma: A model for adjuvant chemotherapy and the rationale for the timing of thoracic surgery. Cancer 41: 841-849, 1978.

2. Glasser DB, Lane JM, Huvos AG, Marcove RC and Rosen G: Survival, prognosis and therapeutic response in osteogenic sarcoma. The Memorial Hospital experience. Cancer 69: 698-708, 1992.

3. Bacci G, Longhi A, Versari M, Mercuri M, Briccoli A and Picci P: Prognostic factors for osteosarcoma of extremity treated with neoadjuvant chemotherapy. Cancer 106: 1154-1161, 2006.

4. Uchida A, Myoui A, Araki N, Yoshikawa H, Shinto Y and Ueda T: Neoadjuvant chemotherapy for pediatric osteosarcoma patients. Cancer 79: 411-415, 1997.

5. Meyers PA, Heller G, Healey J, Huvos A, Lane J, Marcove R, Applewhite A, Vlamis V and Rosen G: Chemotherapy for nonmetastatic osteogenic sarcoma: the Memorial Sloan-Kettering experience. J Clin Oncol 10: 5-15, 1992.

6. Asai T, Ueda T, Itoh K, Yoshioka K, Aoki Y, Mori S and Yoshikawa $\mathrm{H}$ : Establishment and characterization of a murine osteosarcoma cell line (LM8) with high metastatic potential to the lung. Int J Cancer 76: 418-422, 1998.

7. Vogel KG, Paulsson M and Heinegard D: Specific inhibition of type I and II collagen fibrillogenesis by the small proteoglycan of tendon. Biochem J 223: 587-597, 1984.

8. Hocking AM, Shinomura T and McQuillan DJ: Leucine-rich repeat glycoproteins of the extracellular matrix. Matrix Biol 17: 1-9, 1998.

9. Choi HU, Johnson TL, Pal S, Tang L, Rosenberg L and Neame PJ: Characterization of dermatan sulfate proteoglycans, DS-PG I and DS-PG II from articular cartilage and skin isolated by octylsepharose chromatography. J Biol Chem 264: 2876-2884, 1989.

10. Franzen A and Heinegard D: Characterization of proteoglycans from the calcified matrix of bovine bone. Biochem J 224: 59-66, 1984.

11. Lewandowska K, Choi HU, Rosenberg LC, Zardi L and Culp LA: Fibronectin-mediated adhesion of fibroblasts: inhibition by dermatan sulfate proteoglycan and evidence for a cryptic glycosaminoglycan-binding domain. J Cell Biol 105: 1443-1454, 1987.

12. Derynck R, Akhurst RJ and Balmain A: TGF-beta signaling in tumor suppression and cancer progression. Nat Genet 29: 117-129, 2001.

13. Davies CL, Melder RJ, Munn LL, Mouta-Carreira C, Jain RK and Boucher Y: Decorin inhibits endothelial migration and tube-like structure formation: role of thrombospondin-1. Microvasc Res 62: $26-42,2001$ 
14. Merle B, Malaval L, Lawler J, Delmas P and Clezardin P: Decorin inhibits cell attachment to thrombospondin-1 by binding to a KKTR-dependent cell adhesive site present within the N-terminal domain of thrombospondin-1. J Cell Biochem 67: 75-83, 1997

15. Yamaguchi Y, Mann DM and Ruoslahti E: Negative regulation of transforming growth factor- $\beta$ by the proteoglycan decorin. Nature 346: 281-284, 1990.

16. Dugan TA, Yang VW, McQuillan DJ and Hook M: Decorin binds fibrinogen in a $\mathrm{Zn}^{2+}$-dependent interaction. J Biol Chem 278: 13655-13662, 2003 .

17. Nadesalingam J, Bernal AL, Dodds AW, Willis AC, Mahoney DJ, Day AJ, Reid KB and Palaniyar N: Identification and characterization of a novel interaction between pulmonary surfactant protein D and decorin. J Biol Chem 278: 25678-25687, 2003.

18. Desnoyers L, Arnott D and Pennica D: WISP-1 binds to decorin and biglycan. J Biol Chem 276: 47599-47607, 2001

19. Iozzo RV, Moscatello DK, McQuillan DJ and Eichstetter I: Decorin is a biological ligand for the epidermal growth factor receptor. J Biol Chem 274: 4489-4492, 1999.

20. Csordás G, Santra M, Reed CC, Eichstetter I, McQuillan DJ, Gross D, Nugent MA, Hajnóczky G and Iozzo RV: Sustained down-regulation of the epidermal growth factor receptor by decorin. A mechanism for controlling tumor growth in vivo. J Biol Chem 275: 32879-32887, 2000.

21. Moscatello DK, Santra M, Mann DM, McQuillan DJ, Wong AJ and Iozzo RV: Decorin suppresses tumor cell growth by activating the epidermal growth factor receptor. J Clin Invest 101: 406-412, 1998

22. De Luca A, Santra M, Baldi A, Giordano A and Iozzo RV: Decorin-induced growth suppression is associated with upregulation of $\mathrm{p} 21$, an inhibitor of cyclin-dependent kinases. J Biol Chem 271: 18961-18965, 1996.

23. Patel S, Santra M, McQuillan DJ, Iozzo RV and Thomas AP: Decorin activates the epidermal growth factor receptor and elevates cytosolic $\mathrm{Ca}^{2+}$ in A431 carcinoma cells. J Biol Chem 273: 3121-3124, 1998.

24. Santra M, Reed CC and Iozzo RV: Decorin binds to a narrow region of the epidermal growth factor (EGF) receptor, partially overlapping but distinct from the EGF-binding epitope. J Biol Chem 277: 35671-35681, 2002.

25. Kresse H and Schonherr E: Proteoglycans of the extracellular matrix and growth control. J Cell Physiol 189: 266-274, 2001.

26. Reed CC, Gauldie J and Iozzo RV: Suppression of tumorigenicity by adenovirus-mediated gene transfer of decorin. Oncogene 21: 3688-3695, 2002.

27. Santra M, Mann DM, Mercer EW, Skorski T, Calabretta B and Iozzo RV: Ectopic expression of decorin protein core causes a generalized growth suppression in neoplastic cells of various histogenetic origin and requires endogenous p21, an inhibitor of cyclin-dependent kinases. J Clin Invest 100: 149-157, 1997.

28. Santra M, Eichstetter I and Iozzo RV: An anti-oncogenic role for decorin. Down-regulation of ErbB2 leads to growth suppression and cytodifferentiation of mammary carcinoma cells. J Biol Chem 275: 35153-35161, 2000.

29. Leygue E, Snell L, Dotzlaw H, Troup S, Hiller-Hitchcock T, Murphy LC, Roughley PJ and Watson PH: Lumican and decorin are differentially expressed in human breast carcinoma. J Pathol 192: 313-320, 2000 .

30. Nash MA, Deavers MT and Freedman RS: The expression of decorin in human ovarian tumors. Clin Cancer Res 8: 1754-1760, 2002.

31. Köninger J, Giese NA, di Mola FF, Berberat P, Giese T, Esposito I, Bachem MG, Büchler MW and Friess H: Overexpressed decorin in pancreatic cancer: potential tumor growth inhibition and attenuation of chemotherapeutic action. Clin Cancer Res 10: 4776-4783, 2004.

32. Köninger J, Giese T, di Mola FF, Wente MN, Esposito I, Bachem MG, Giese NA, Büchler MW and Friess H: Pancreatic tumor cells influence the composition of the extracellular matrix. Biochem Biophys Res Commun 322: 943-949, 2004.

33. Skandalis SS, Theocharis AD, Theocharis DA, Papadas T, Vynios DH and Papageorgakopoulou N: Matrix proteoglycans are markedly affected in advanced laryngeal squamous cell carcinoma. Biochim Biophys Acta 1689: 152-161, 2004.

34. Santra M, Skorski T, Calabretta B, Lattime EC and Iozzo RV: De novo decorin gene expression suppresses the malignant phenotype in human colon cancer cells. Proc Natl Acad Sci USA 92: 7016-7020, 1995 .

35. Schönherr E, Levkau B, Schaefer L, Kresse H and Walsh K: Decorin-mediated signal transduction in endothelial cells. Involvement of Akt/protein kinase B in up-regulation of p21 ${ }^{\text {WAF1/CIPl }}$ but not p27 ${ }^{\mathrm{KIP} 1}$. J Biol Chem 276: 40687-40692, 2001.
36. Shi X, Friess H, Kleeff J, Ozawa F and Buchler MW: Pancreatic cancer: factors regulating tumor development, maintenance and metastasis. Pancreatology 1: 517-524, 2001.

37. Grant DS, Yenisey C, Rose RW, Tootell M, Santra M and Iozzo RV: Decorin suppresses tumor cell-mediated angiogenesis. Oncogene 21: 4765-4777, 2002.

38. Troup S, Njue C, Kliewer EV, Parisien M, Roskelley C, Chakravarti S, Roughley PJ, Murphy LC and Watson PH: Reduced expression of the small leucine-rich proteoglycans, lumican, and decorin is associated with poor outcome in node-negative invasive breast cancer. Clin Cancer Res 9: 207-214, 2003.

39. Reed CC, Waterhouse A, Kirby S, Kay P, Owens RT, McQuillan DJ and Iozzo RV: Decorin prevents metastatic spreading of breast cancer. Oncogene 24: 1104-1110, 2005.

40. Brown LF, Guidi AJ, Schnitt SJ, Van De Water L, Iruela-Arispe ML, Yeo TK, Tognazzi K and Dvorak HF: Vascular stroma formation in carcinoma in situ, invasive carcinoma, and metastatic carcinoma of the breast. Clin Cancer Res 5: 1041-1056, 1999.

41. Theocharis AD, Vynios DH, Papageorgakopoulou N, Skandalis SS and Theocharis DA: Altered content composition and structure of glycosaminoglycans and proteoglycans in gastric carcinoma. Int J Biochem Cell Biol 35: 376-390, 2003.

42. Harada T, Shinohara M, Nakamura S and Oka M: An immunohistochemical study of the extracellular matrix in oral squamous cell carcinoma and its association with invasive and metastatic potential. Virchows Arch 424: 257-266, 1994.

43. Miyasaka Y, Enomoto N, Nagayama K, Izumi N, Marumo F, Watanabe $\mathrm{M}$ and Sato C: Analysis of differentially expressed genes in human hepatocellular carcinoma using suppression subtractive hybridization. Br J Cancer 85: 228-234, 2001.

44. Matsumine A, Shintani K, Kusuzaki K, Matsubara T, Satonaka H, Wakabayashi T, Iino T and Uchida A: Expression of decorin, a small leucine-rich proteoglycan, as a prognostic factor in soft tissue tumors. J Surg Oncol (In press).

45. Poste G and Fidler IJ: The pathogenesis of cancer metastasis Nature 283: 139-146, 1980

46. Mialou V, Philip T, Kalifa C, Perol D, Gentet JC, Marec-Berard P, Pacquement H, Chastagner P, Defaschelles AS and Hartmann O: Metastatic osteosarcoma at diagnosis: prognostic factors and long-term outcome - the French pediatric experience. Cancer 104: 1100-1109, 2005.

47. Mueller MM and Fusenig NE: Friends or foes - bipolar effects of the tumour stroma in cancer. Nat Rev Cancer 4: 839-849, 2004.

48. Iozzo RV: Tumor stroma as a regulator of neoplastic behavior. Agonistic and antagonistic elements embedded in the same connective tissue. Lab Invest 73: 157-160, 1995.

49. Nash MA, Loercher AE and Freedman RS: In vitro growth inhibition of ovarian cancer cells by decorin: Synergism of action between decorin and carboplatin. Cancer Res 59: 6192-6196, 1999.

50. Tralhão JG, Schaefer L, Micegova M, Evaristo C, Schönherr E, Kayal S, Veiga-Fernandes H, Danel C, Iozzo RV, Kresse H and Lemarchand P: In vivo selective and distant killing of cancer cells, using adenovirus-mediated decorin gene transfer. FASEB J 17: 464-466, 2003

51. McQuillan DJ, Richardson MD and Bateman JF: Matrix deposition by a calcifying human osteogenic sarcoma cell line (SAOS-2). Bone 16: 415-426, 1995

52. Weidner N, Semple JP, Welch WR and Folkman J: Tumor angiogenesis and metastasis - correlation in invasive breast carcinoma. N Engl J Med 324: 1-8, 1991.

53. Macchiarini P, Fontanini G, Hardin MJ, Squartini F and Angeletti CA: Relation of neovascularisation to metastasis of non-small-cell lung cancer. Lancet 340: 145-146, 1992.

54. Kaya M, Wada T, Akatsuka T, Kawaguchi S, Nagoya S, Shindoh M, Higashino F, Mezawa F, Okada F and Ishii S: Vascular endothelial growth factor expression in untreated osteosarcoma is predictive of pulmonary metastasis and poor prognosis. Clin Cancer Res 6: 572-577, 2000.

55. Kinsella MG, Fischer JW, Mason DP and Wight TN: Retrovirally mediated expression of decorin by macrovascular endothelial cells. Effects on cellular migration and fibronectin fibrillogenesis in vitro. J Biol Chem 275: 13924-13932, 2000.

56. Merle B, Durussel L, Delmas P and Clezardin P: Decorin inhibits cell migration through a process requiring its glycosaminoglycan side chain. J Cell Biochem 75: 538-546, 1999.

57. Mimeault $\mathrm{M}$ and Batra SK: Functions of tumorigenic and migrating cancer progenitor cells in cancer progression and metastasis and their therapeutic implications. Cancer Metastasis Rev 26: 203-214, 2007. 